\title{
Torsion of cylindrically anisotropic nano/microtubes of the cubic crystals obtained by rolling the crystal planes (011)
}

\author{
R.V. Goldstein, V.A. Gorodtsov, D.S. Lisovenko ${ }^{\dagger}$ \\ †lisovenk@ipmnet.ru
}

Institute for Problems in Mechanics, Russian Academy of Sciences, Prosp. Vernadskogo 101-1, 119526 Moscow, Russia

Elastic torsion of cylindrically anisotropic nano/microtubes is examined by Saint-Venant approach. It is assumed that the tubes were obtained by rolling the plates of the cubic crystals with plane orientation (011). The analytical expression for the torsional stiffness of such nano/microtubes is obtained. It is found, that the torsional stiffness is dependent on the three compliance coefficients of cubic crystal: thickness parameter, chirality angle and radius of the tube. Numerical analysis of the torsional stiffness of nano/microtubes is given. It was shown that for most of crystals the dimensionless ratio of torsional stiffness to torsional stiffness at zero chiral angle of nano/microtubes slightly varies with the thickness parameter of tubes. Materials with the substantial change in the dimensionless ratio of torsional stiffnesses are found. It is shown, that the torsion of chiral nano/microtubes obtained from cubic crystal plates in the absence of tensile forces is accompanied by linear Poynting's effect. Comparative analysis of the dimensionless ratios of torsional stiffness to torsional stiffness at zero chirality angle for nano/microtubes obtained by rolling the crystal planes (001) and (011) is given. It is shown that the variability of torsional stiffness for nano/microtubes obtained by rolling the crystal planes (011) is much higher than for nano/microtubes produced by rolling the crystal planes (001). Comparative analysis of linear Poynting's effect for nano/microtubes created by rolling the crystal planes (001) and (011) is also presented.

Keywords: nanotubes, microtubes, torsion, anisotropy, Poynting's effect.

\section{Кручение цилиндрически-анизотропных нано/микротрубок из кубических материалов, полученных сворачиванием кристаллофизических плоскостей (011)}

\author{
Гольдштейн Р.В., Городцов В.А., Лисовенко Д.С. ${ }^{\dagger}$ \\ †lisovenk@ipmnet.ru
}

Институт проблем механики им. А.Ю. Ишлинского РАН. 119526, Москва, просп. Вернадского, д.101, корп.1

В рамках теории упругости анизотропного тела рассмотрено кручение цилиндрически-анизотропных нано- и микротрубок методом Сен-Венана. Было предположено, что нано- и микротрубки получались сворачиванием кристаллической пластины из кубических кристаллов с ориентацией плоскости (011). Получено аналитическое выражение крутильной жесткости для таких нано- и микротрубок. Найдено, что крутильная жесткость зависит от трех модулей податливостей кубического кристалла, параметра толщины, угла хиральности и радиуса трубки. Дан численный анализ крутильных жесткостей нано- и микротрубок из некоторых кубических материалов. Анализ показал, что для большинства материалов безразмерное отношение крутильной жесткости к крутильной жесткости при нулевом угле хиральности для нано- и микротрубок слабо меняется с изменением параметра толщины. Выявлены материалы, для которых есть существенное изменение безразмерного отношения крутильных жесткостей. Показано, что кручение хиральных нано- и микротрубок из кубических материалов даже в отсутствие растягивающих усилий сопровождается линейным эффектом Пойнтинга. Дан сравнительный анализ безразмерных отношений крутильных жесткостей к крутильным жесткостям при нулевом угле хиральности для нано- и микротрубок, полученных сворачиванием кристаллических плоскостей (001) и (011). Показано, что изменчивость крутильных жесткостей для нано- и микротрубок, полученных сворачиванием кристаллических плоскостей (011), оказывается существенно выше, чем для нано- и микротрубок, полученных сворачиванием кристаллических плоскостей (001). Также проведен сравнительный анализ линейного эффекта Пойнтинга для нано- и микротрубок, полученных сворачиванием кристаллических плоскостей (001) и (011).

Ключевые слова: нанотрубки, микротрубки, кручение, анизотропия, эффект Пойнтинга. 


\section{Introduction}

Many nano- and mesomaterials were synthesized in the form of nanotubes and microtubes. Nano/microtubes were obtained, for example, by rolling thin crystalline plates into tubes $[1-7]$. This method makes it possible to obtain nanoand microtubes from almost all crystalline materials.

To describe mechanical properties of nano- and microtubes in the framework continuum mechanics it is often used a model of a cylindrical shell (see, e.g., the reviews $[8,9])$. A model of a hollow cylindrical rod was proposed in [10-12]. This model is acceptable for describing the carbon and non-carbon nano/microtubes with curvilinear cubic, hexagonal, rhombohedral and tetragonal anisotropy. It has been shown by the example of the problem on extension the nano/microtubes obtained by rolling the crystal planes (001), that such tubes can have negative Poisson's ratio [10 - 12] and manifest linear Poynting's effect [13]. Below we will consider the problem on torsion nano/microtubes, obtained by rolling the cubic crystal planes (011), in the framework of the model of a hollow cylindrical rod.

\section{From rectilinear-anisotropic cubic crystals to cylindrically anisotropic nano/microtubes}

The method of rolling thin crystal plates is one of the most effective methods of nanotubes and microtubes fabrication from single crystals. The elastic properties of the produced tubes can be described in terms of the elasticity theory, if the thicknesses of their walls are significantly higher than the atomic and interatomic distances, i.e. several nanometers [14].

We assume that the crystal plate with orientation (011) is rolled into a cylindrical tube so that the axis which is perpendicular to the plane (011) passes into the radial axis of the tube. Other crystal axis which is rotated by an angle $\chi$ relative to the crystallographic axis in the plate corresponds to the longitudinal axis of the tube (see Fig. 6 in [12]). The symmetry of formed curvilinear anisotropic tube is reduced relative to the initial cubic symmetry of the crystal due to the rotation to the specified chiral angle. Its symmetry corresponds to the symmetry of the monoclinic system with thirteen compliance coefficients $s_{11}^{\prime}, s_{12}^{\prime}, s_{22}^{\prime}, s_{13}^{\prime}, s_{23}^{\prime}, s_{33}^{\prime}, s_{44}^{\prime}, s_{55}^{\prime}$, $s_{66}^{\prime}, s_{45}^{\prime}, s_{16}^{\prime}, s_{26}^{\prime}, s_{36}^{\prime}$, depending on the chiral angle $\chi$ and the initial three cubic crystal compliances $s_{i j}$ as follows

$$
\begin{gathered}
s_{11}^{\prime}=s_{11}-2 \Delta \sin ^{2} \chi \cos ^{2} \chi-0.5 \Delta \sin ^{4} \chi \\
s_{22}^{\prime}=s_{11}-2 \Delta \sin ^{2} \chi \cos ^{2} \chi-0.5 \Delta \cos ^{4} \chi \\
s_{33}^{\prime}=s_{11}-0.5 \Delta, \quad s_{12}^{\prime}=s_{12}+1.5 \Delta \sin ^{2} \chi \cos ^{2} \chi \\
s_{13}^{\prime}=s_{12}+0.5 \Delta \sin ^{2} \chi, \quad s_{23}^{\prime}=s_{12}+0.5 \Delta \cos ^{2}, \\
s_{44}^{\prime}=s_{44}+2 \Delta \cos ^{2} \chi, \quad s_{55}^{\prime}=s_{44}+2 \Delta \sin ^{2} \chi \\
s_{45}^{\prime}=\Delta \sin 2 \chi, \quad s_{36}^{\prime}=0.5 \Delta \sin 2 \chi \\
s_{16}^{\prime}=0.5 \Delta \sin 2 \chi\left(1-3 \cos ^{2} \chi\right), \\
s_{26}^{\prime}=0.5 \Delta \sin 2 \chi\left(1-3 \sin ^{2} \chi\right), \\
s_{66}^{\prime}=s_{44}+1.5 \Delta \sin ^{2} 2 \chi \\
2 \Delta \equiv 2 s_{11}-2 s_{12}-s_{44},
\end{gathered}
$$

The dependences of the coefficients $s_{i j}^{\prime}$ on chiral angle are periodic with period $\pi$.

Curvilinear-anisotropic elasticity of nano/microtubes thus characterized by linear equations of Hooke's law

$$
\begin{gathered}
u_{z z}=s_{11}^{\prime} \sigma_{z z}+s_{11}^{\prime} \sigma_{\varphi \varphi}+s_{13}^{\prime} \sigma_{r r}-s_{16}^{\prime} \sigma_{\varphi z}, \\
u_{\varphi \varphi}=s_{12}^{\prime} \sigma_{z z}+s_{22}^{\prime} \sigma_{\varphi \varphi}+s_{23}^{\prime} \sigma_{r r}-s_{26}^{\prime} \sigma_{\varphi z}, \\
u_{r r}=s_{13}^{\prime} \sigma_{z z}+s_{23}^{\prime} \sigma_{\varphi \varphi}+s_{33}^{\prime} \sigma_{r r}-s_{36}^{\prime} \sigma_{\varphi z}, \\
2 u_{\varphi z}=s_{66}^{\prime} \sigma_{\varphi z}-s_{16}^{\prime} \sigma_{z z}-s_{26}^{\prime} \sigma_{\varphi \varphi}-s_{36}^{\prime} \sigma_{r r}, \\
2 u_{r z}=s_{55}^{\prime} \sigma_{r z}-s_{45}^{\prime} \sigma_{\varphi r}, \quad 2 u_{r \varphi}=-s_{45}^{\prime} \sigma_{r z}+s_{44}^{\prime} \sigma_{\varphi r} .
\end{gathered}
$$

\section{Torsion of nano/microtubes obtained by rolling the crystal planes (011)}

We will consider the problem on torsion of curvilinearanisotropic nano/microtubes, obtained by rolling the crystal planes (011) of a cubic crystal. Let the integral boundary conditions

$$
P_{z}=\int \sigma_{z z} d S=0, \quad M_{z}=\int \sigma_{\varphi z} r d S
$$

are satisfied at the ends of tubes $\left(P, M_{z}\right.$ are the total tensile force and torsion moment, respectively). Tension is absent and full torque is given. Local conditions of the absence of stress on the sides of the hollow tubes, i.e. on the inner surface $r=r_{0}$ and outer surface $r=R_{0} \equiv r_{0} \rho$, are assumed.

Later we will assume that there is an axially symmetric radial-inhomogeneous stress state $\sigma_{r r}(r), \quad \sigma_{\varphi \varphi}(r), \quad \sigma_{z z}(r)$, $\sigma_{r \varphi}(r), \sigma_{r z}(r), \sigma_{\varphi z}(r)$. Then the equilibrium equations are simplified

$$
\begin{gathered}
\sigma_{\varphi \varphi}(r)=\frac{d}{d r}\left(r \sigma_{r r}(r)\right), \\
\frac{d}{d r}\left(r \sigma_{r z}(r)\right)=0, \frac{d}{d r}\left(r^{2} \sigma_{r \varphi}(r)\right)=0 .
\end{gathered}
$$

The last two equations (5) and the zero boundary conditions on the side surfaces of the tube lead to $\sigma_{r \varphi}(r)=\sigma_{r z}(r)=0$. This in turn leads to a simplification of the equations of Hooke's law, which will contain now three normal stresses $\sigma_{r r}(r), \sigma_{\varphi \varphi}(r)$, $\sigma_{z z}(r)$, and one shear stress $\sigma_{\varphi z}(r)$. The deformations are also radially inhomogeneous according to these equations. They allow to obtain unambiguous displacements if the following constraints are satisfied

$$
\begin{aligned}
u_{z z}(r)=\varepsilon, \quad u_{r r}(r) & =\frac{d}{d r}\left(r u_{\varphi \varphi}(r)\right), \quad 2 u_{\varphi z}(r)=\tau r, \\
\varepsilon & =\text { const }, \quad \tau=\text { const. }
\end{aligned}
$$

The condition (6), together with the equilibrium equation (4) and the equations of Hooke's law allow us to express all stresses through the one component $\sigma_{r r}(r)$ that satisfies the differential equation of the second order

$\frac{d}{d r}\left(r \frac{d}{d r}\left(r \sigma_{r r}(r)\right)\right)=a_{0} \sigma_{r r}(r)+a_{1}\left(1-a_{0}\right) \varepsilon+a_{2}\left(4-a_{0}\right) \tau r$,

where

$$
\begin{gathered}
a_{0} \equiv \frac{t_{11} t_{33}-t_{13}^{2}}{t_{11} t_{22}-t_{12}^{2}}, \quad a_{1} \equiv \frac{t_{13}-t_{12}}{t_{11}\left(t_{22}-t_{33}\right)+t_{13}^{2}-t_{12}^{2}}, \\
a_{2} \equiv \frac{1}{s_{66}^{\prime}} \frac{s_{16}^{\prime}\left(t_{13}-2 t_{12}\right)+\left(2 s_{26}^{\prime}-s_{36}^{\prime}\right) t_{11}}{t_{11}\left(4 t_{22}-t_{33}\right)+t_{13}^{2}-4 t_{12}^{2}}, \\
t_{m n} \equiv s_{m n}^{\prime}-\frac{s_{m 6}^{\prime} s_{m 6}^{\prime}}{s_{66}^{\prime}} .
\end{gathered}
$$

The solution of this equation for the stress component $\sigma_{r r}(r)$ 
has the powerlike form

$$
\sigma_{r r}(r)=a_{1} \varepsilon+a_{2} \tau r_{0}\left(\frac{r}{r_{0}}\right)+\sum_{ \pm} A_{ \pm}\left(\frac{r}{r_{0}}\right)^{\lambda_{ \pm}}, \quad \lambda_{ \pm}=-1 \pm \sqrt{a_{0}} .
$$

The remaining stress components have a similar structure. Using the equilibrium equations (4), (5), Hooke's law (2), and the additional conditions (6), we find

$$
\begin{gathered}
\sigma_{\varphi \varphi}(r)=a_{1} \varepsilon+2 a_{2} \tau r_{0}\left(\frac{r}{r_{0}}\right)+\sum_{ \pm}\left(1+\lambda_{ \pm}\right) A_{ \pm}\left(\frac{r}{r_{0}}\right)^{\lambda_{ \pm}} \\
t_{11} \sigma_{z z}(r)=\left[1-a_{1}\left(t_{12}+t_{13}\right)\right] \varepsilon+\left[\frac{s_{16}^{\prime}}{s_{66}^{\prime}}-a_{2}\left(2 t_{12}+t_{13}\right)\right] \tau r_{0}\left(\frac{r}{r_{0}}\right)- \\
-\sum_{ \pm}\left[t_{13}+t_{12}\left(1+\lambda_{ \pm}\right)\right] A_{ \pm}\left(\frac{r}{r_{0}}\right)^{\lambda_{ \pm}}, \\
+\left[1+\frac{s_{16}^{\prime 2}}{s_{66}^{\prime} t_{11}^{\prime}}+a_{2}^{\prime}\left(2 s_{26}^{\prime}+s_{36}^{\prime}-s_{16}^{\prime} \frac{2 t_{12}+t_{13}}{t_{11}}\right)\right] \tau r_{0}\left(\frac{r}{r_{0}}\right)+ \\
+\sum_{ \pm}^{\prime}\left[s_{36}^{\prime}-s_{16}^{\prime} \frac{t_{13}}{t_{11}}+\left(s_{26}^{\prime}-s_{16}^{\prime} \frac{t_{12}}{t_{11}}\right)\left(1+s_{26}^{\prime}+s_{36}^{\prime}-s_{16}^{\prime} \frac{t_{12}+t_{13}}{t_{11}}\right)\right] A_{ \pm}\left(\frac{r}{r_{0}}\right)^{\lambda_{ \pm}}
\end{gathered}
$$

The obtained representations of stress components contain four parameters $\varepsilon, \tau, A_{+}, A_{-}$. The boundary conditions of the stress absence on the inner and outer walls of the cylindrical tubes allow us to express $A_{+}, A_{-}$through $\varepsilon, \tau$ as follows

$$
\begin{aligned}
& A_{+}=a_{1} \frac{\rho^{\lambda_{-}}-1}{\rho^{\lambda_{+}}-\rho^{\lambda_{-}}} \varepsilon+a_{2} \frac{\rho^{\lambda_{-}}-\rho}{\rho^{\lambda_{+}}-\rho^{\lambda_{-}}} \tau r_{0}, \\
& A_{-}=a_{1} \frac{1-\rho^{\lambda_{+}}}{\rho^{\lambda_{+}}-\rho^{\lambda_{-}}} \varepsilon+a_{2} \frac{\rho-\rho^{\lambda_{+}}}{\rho^{\lambda_{+}}-\rho^{\lambda_{-}}} \tau r_{0} .
\end{aligned}
$$

Here, the thickness parameter $\rho \equiv R_{0} / r_{0}$ is the ratio of the outer radius to the inner radius of the tube.

The integration of $\sigma_{z z}(r)$ and $\sigma_{\varphi z}(r) r$ on the tube crosssectional area allows one to fulfill the integral conditions (2). We ultimately obtain relationship between the parameters $\varepsilon, \tau$, and the dependence of torsional stiffness $C=M_{z} / \tau$ on the tube radius, ratio of internal and external radii $\rho \equiv R_{0} / r_{0}$, compliances $s_{i j}$ and chiral angle $\chi$ (see expressions $s_{i j}^{\prime}$, $t_{i j}$ though $s_{i j}, \chi$ in (1), (8))

$$
\begin{gathered}
C=\frac{2 \pi}{s_{66}^{\prime}} r_{0}^{4}\left\{\Gamma\left[\frac{s_{16}^{\prime}}{t_{11}}+a_{1}\left(s_{26}^{\prime}+s_{36}^{\prime}-s_{16}^{\prime} \frac{t_{12}+t_{13}}{t_{11}}\right)\right] \frac{\rho^{3}-1}{3}+\right. \\
+\left[1+\frac{s_{16}^{\prime 2}}{s_{66}^{\prime} t_{11}}+a_{2}\left(s_{36}^{\prime}+2 s_{26}^{\prime}-s_{16}^{\prime} \frac{t_{13}+2 t_{12}}{t_{11}}\right)\right] \frac{\rho^{4}-1}{4}+ \\
\left.+\sum_{ \pm}\left[s_{36}^{\prime}-s_{16}^{\prime} \frac{t_{13}}{t_{11}}+\left(s_{26}^{\prime}-s_{16}^{\prime} \frac{t_{12}}{t_{11}}\right)\left(1+\lambda_{ \pm}\right)\right] \Omega_{ \pm} \frac{\rho^{\lambda_{ \pm}+3}-1}{\lambda_{ \pm}+3}\right\}, \\
\Omega_{ \pm} \equiv \frac{a_{2}\left(\rho^{\lambda_{\mp}}-\rho\right)+\Gamma a_{1}\left(\rho^{\lambda_{\mp}}-1\right)}{\rho^{\lambda_{ \pm}}-\rho^{\lambda_{\mp}}}, \\
\Gamma=-\Gamma_{1} / \Gamma_{2}, \\
\Gamma_{1}=\left[\frac{s_{16}^{\prime}}{s_{66}^{\prime}}-a_{2}\left(t_{13}+2 t_{12}\right)\right] \frac{\rho^{3}-1}{3}- \\
\Gamma=-\Gamma_{1} / \Gamma_{ \pm}
\end{gathered}
$$

$$
\begin{gathered}
\Gamma_{2}=\left[1-a_{1}\left(t_{12}+t_{13}\right)\right] \frac{\rho^{2}-1}{2}- \\
-a_{1} \sum_{ \pm}\left[t_{13}+t_{12}\left(1+\lambda_{ \pm}\right)\right] \frac{\rho^{\lambda_{ \pm}+2}-1}{\lambda_{ \pm}+2} \frac{\rho^{\lambda_{F}}-1}{\rho^{\lambda_{ \pm}}-\rho^{\lambda_{F}}} .
\end{gathered}
$$

At zero chiral angle the result for torsional stiffness takes very simple form

$$
\left.C_{0} \equiv C\right|_{\chi=0}=\frac{\pi}{2 s_{44}} r_{0}^{4}\left(\rho^{4}-1\right)
$$

The dimensionless ratio $C / C_{0}$ depends on the dimensionless combinations of compliance coefficients, dimensionless scaling parameter $\rho$ and chiral angle $\chi$. Numerical analysis of torsion was based on experimental data for the cubic crystals from handbook [15] was performed for auxetic nano/microtubes from Table 11 in [12]. The dimensionless ratio $C / C_{0}$ is greater than one for the majority of the nano/ microtubes. However, it could be less than one for thinwalled tubes from $\mathrm{Yb}$, TmSe и $\mathrm{Tm}_{0.99} \mathrm{Se}$. Examples of the dependences of this ratio from $\rho$ and $\chi$ for nano/microtubes of cubic crystals $\mathrm{Tm}_{0.99} \mathrm{Se}$ and $\mathrm{Cu}$ are shown in Fig. 1. Let us note that the anisotropy coefficient $\Delta \equiv s_{11}-s_{12}-0.5 s_{44}$ is negative $(-14.26)$ for $\operatorname{Tm}_{0.99} \mathrm{Se}$ and positive $(+14.65)$ for $\mathrm{Cu}$. It was found that the ratio $C / C_{0}$ increases slightly with increasing thickness parameter. The growth of $C / C_{0}$ is most noticeable during the angular surroundings of $\chi=5 \pi / 16$ and $\chi=11 \pi / 16$.

Received higher connection of parameters $\varepsilon, \tau$ reflects the effect of occurrence of longitudinal strain of tubes in their torsion, Poynting's effect. The effect, experimentally observed originally by Poynting, was nonlinear [16]. Here, the connection of $\varepsilon$ with $\tau$ is linear due to the linearity of Hooke's law. The dimensionless proportionality coefficient $\Gamma=\varepsilon /\left(\tau r_{0}\right)$ depends on the relative thickness of the walls of the tubes $(\rho-1)$, dimensionless combinations of three compliance coefficients $s_{11}, s_{12}, s_{44}$ and chiral angle $\chi$. The dependence of the effect on chiral angle is odd, and in particular, disappears when $\chi=0$, and when $\chi=\pi / 2$. It can be seen from the above formulas and Fig. 2. The oscillating character of linear Poynting's effect can also be seen from this figure.

It should be noted that the differences exist between the nano/microtubes obtained by rolling the crystal planes (001) and (011). Comparisons are given for the dimensionless ratio of torsional stiffnesses $C / C_{0}$ and the dimensionless coefficients $\Gamma$ for nano/microtubes obtained by rolling the crystal planes (001) and (011) of cubic crystals $\mathrm{Tm}_{0.99} \mathrm{Se}$
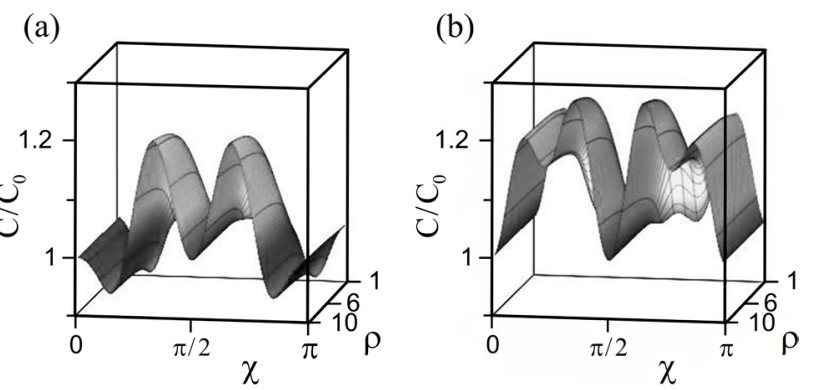

Fig. 1. The dependences of the ratio $C / C_{0}$ on the chiral angle $\chi$ and the thickness parameter $\rho$ for the nano/microtubes from the cubic crystal of $\mathrm{Tm}_{0.99} \mathrm{Se}(\mathrm{a})$ and $\mathrm{Cu}(\mathrm{b})$. 
(with negative anisotropy coefficient) and $\mathrm{Cu}$ (with positive anisotropy coefficient) in Fig. 3. In this figure lines 1 and 2 correspond to the values of $C / C_{0}$ and $\Gamma$ for nano/microtubes from copper, obtained by rolling the crystal plane (001) and (011) respectively, and lines 3 and 4 correspond to nano/microtubes from $\mathrm{Tm}_{0.99} \mathrm{Se}$. From Fig. $3 \mathrm{a}$ it is seen that the dimensionless ratio of torsional stiffness $C / C_{0}$ for thin nano/microtubes from $\mathrm{Tm}_{0.99} \mathrm{Se}$ and $\mathrm{Cu}$ crystals, obtained by rolling the crystal planes (001), differs only slightly from unity. Dependence $C / C_{0}$ for nano/microtubes from $\mathrm{Tm}_{0.99} \mathrm{Se}$ is not presented in Fig 3a since it practically coincides with the dependence $C / C_{0}$ for nano/microtubes of $\mathrm{Cu}$. As can be seen from Fig. $3 \mathrm{~b}$ the dimensionless coefficient $\Gamma$ varies more for thin-walled $\mathrm{Cu}$ nano/microtubes, obtained by rolling the crystal planes (001) than for the tubes fabricated by rolling the crystal planes (011). In the case of thin-walled $\mathrm{Tm}_{0.99} \mathrm{Se}$ tubes the reverse situation occurs. The analysis carried out for nano/microtubes from other cubic crystals, presented in Table 11 [12], shows similar behavior of coefficient $\Gamma$ for the tubes fabricated by rolling the crystal planes (001) and (011), depending on the sign of the anisotropy coefficient.

\section{Conclusion}

Torsional stiffness of chiral nano/microtubes fabricated by rolling the crystal planes (011) of cubic crystals is proportional to the difference between the fourth power of the external and internal radii at zero chiral angle. Torsional stiffness, made dimensionless by dividing on the torsional stiffness at zero chirality depends on the dimensionless ratio of the external and internal radii, dimensionless combinations of elastic compliances and chiral angle. Numerical analysis of this dimensionless ratio showed that in most cases the
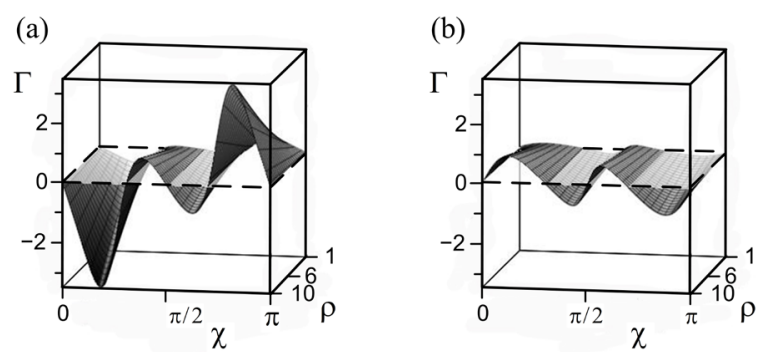

Fig. 2. The dependences of $\Gamma$ on the chiral angle $\chi$ and the thickness parameter $\rho$ for the nano/microtubes from the cubic crystal of $\mathrm{Tm}_{0.99} \mathrm{Se}(\mathrm{a})$ and $\mathrm{Cu}(\mathrm{b})$.
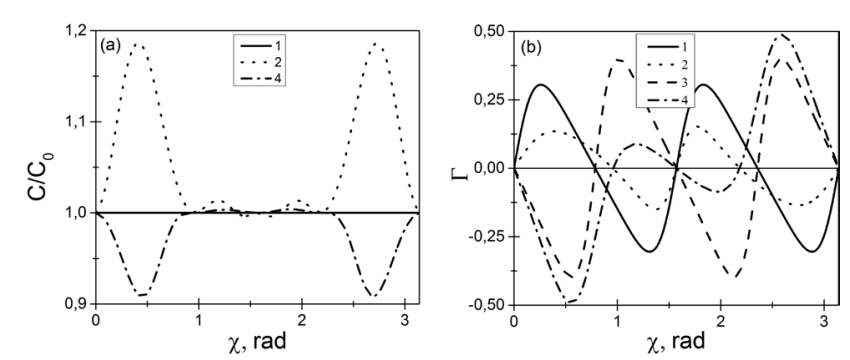

Fig. 3. The dependences of $C / C_{0}$ (a) and $\Gamma$ (b) on the chiral angle $\chi$ for the thin nano/microtubes from the cubic crystal of $\mathrm{Tm}_{0.99} \mathrm{Se}$ and $\mathrm{Cu}$. The lines 1 and 2 correspond to the values of $C / C_{0}$ and $\Gamma$ to nano/microtubes from copper, obtained by rolling the crystal plane (001) and (011) respectively, and lines 3 and 4 correspond to nano/ microtubes from $\mathrm{Tm}_{0.99}$ Se. dimensionless ratio of torsional stiffness slightly increases with increasing the thickness parameter of tubes at a fixed chiral angle. This ratio can increase substantially at a chiral angle close to $5 \pi / 16$ or $11 \pi / 16$. Torsion of chiral nano/ microtubes of cubic crystals is accompanied by changes in their length, even in the absence of tensile forces. Such Poynting's effect disappears in special cases of chiral angles equal to 0 and $\pi / 2$. Nano/microtubes lengthening or shortening under torsion can occur at different values of the chiral angle.

It is shown that the variability of torsional stiffness for nano/microtubes obtained by rolling the crystal planes (011), is much higher than for nano/microtubes produced by rolling the crystal planes (001). In the case thin-walled nano/microtubes from cubic crystals with a positive anisotropy coefficient, torsion in the case (001) planes can be accompanied by a stronger elongation/shortening than for the nano/microtubes in the case of planes (011). The opposite situation occurs for nano/microtubes from cubic crystals with a negative coefficient of anisotropy.

Acknowledgements. The work was performed within the framework of the Project RFBR 16-01-00325.

\section{References}

1. V. Ya. Prinz, V.A. Seleznev, A.K. Gutakovsky, A. V. Chenovskiy, V.V. Preobrazhenskii, M.A. Putato, T. A. Gavrilova Physica E 6 (1-4) 828 - 831 (2000).

2. S. V. Golod, V. Ya. Prinz, V. I. Mashanov, A. K. Gutakovsky Semicond. Sci. Technolog. 16 (3) $181-185$ (2001).

3. O. G. Schmidt, K. Eberl Nature 410 (6825) 168 (2001).

4. O.G. Schmidt, N. Schmarje, C. Deneke, C. Muller, N.-Y. Jin-Phillipp Adv. Mater 13 (10), 756 - 759 (2001)

5. V. Ya. Prinz Microelectr. Eng. 69 (2-4) $466-475$ (2003).

6. Y. Mei, G. Huang, A. A. Solovev, S. Sanchez, E. B. Urena, I. Monch, F. Ding, T. Reindl, K.Y. Fu, P.K. Chu, O. G. Schmidt Adv. Mater 20 (21) 4085 - 4090 (2008).

7. Y. Mei, A.A. Solovev, S. Sanchez, O.G. Schmidt Chem. Soc. Rev. 40 (5) 2109-2119 (2011).

8. A. V. Eletskii Phys.Usp. 50 (3) 225-261 [А. В. Елецкий УФН 177 (3) 233 - 274 (2007)].

(2007)

9. S. Reich, C. Thomsen, J. Maultzsch Carbon nanotubes: basic concepts and physical properties. Weinheim: WileyVCH. (2004) 467 p.

10. R. V. Goldstein, V.A. Gorodtsov, D.S. Lisovenko Phys. Mesomech. 12 (1-2) 38-53 (2009).

11. R. V. Goldstein, V. A. Gorodtsov, D. S. Lisovenko Doklady Physics 58 (9) 400 - 404. (2013).

12. R. V. Goldstein, V.A. Gorodtsov, D.S. Lisovenko Phys. Mesomech. 17 (2) $97-115$ (2014).

13. R. V. Goldstein, V.A. Gorodtsov, D.S. Lisovenko Phys. Mesomech. 19 (3) $229-238$ (2016).

14. R. V. Goldstein, V.A. Gorodtsov, A.V. Chentsov, S. V. Starikov, V.V. Stegailov, G.E. Norman Letters on Materials 1 (4) 185-189 (2011).

15. Landolt-Börnstein. Group III: Crystal and Solid State Physics. 29a. Second and Higher Order Constants. Berlin. Springer (1992).

16. J. H. Poynting Proc. Roy. Soc. A 82 (557), 546 - 559 (1909). 